\title{
Robust Time Optimization in HD Video Surveillance System
}

\author{
M. Ramamoorthy, N.Ayyanathan, M.Padma Usha, S.Franklin
}

\begin{abstract}
Recent video surveillance system provides a path to continuously monitor any place at any time. In addition IP based surveillance system helps to monitor the place remotely through wide area network. Here the system is designed such that the camera which captures the video act as the front end and the computer which helps as to view the details acts as the client of the system. The main aim of this paper is to increase the resolution of the video in the system and to reduce the transmission time of the IP based video surveillance system. In this system we use IP camera to capture the scene and a field programmable gate array (FPGA) is connected to the local server through the IP network.The FPGA used here is programmed to process the captured video and operates towards effective data transmission in IP network. The algorithms like connected component labeling, background modeling is analyzed along with High Efficiency Video Coding (HEVC) to enhance the quality of the video captured. In futureon updating the designed model Using WAP structure the cell phones can be used for the client side of the system.As expected due to the introduction of efficient video coding and IP networking the transmission time is highly reduced in our proposed system.
\end{abstract}

Keywords- HEVC; FPGA; Video Surveillance; Image Enhancement.

\section{INTRODUCTION}

The Internet and its conventions have experienced various improvements to make this advancement conceivable. Exchanging ongoing video on the web requires amazing methods to accomplish great quality video streameven at low bitrates. The universal institutionalization of these procedures is essential so as to make the applications interoperable. This paper investigates the present condition of strategies and measures utilized in transmission of ongoing video on the Internet.One of the advantages of IP video observation innovation, contrasted and conventional simple video hardware, is that advanced video is compacted and transmitted crosswise over standard Ethernet systems utilizing IP which is a similar convention utilized in corporate systems and the internet.During the most recent couple of years, the fast development of computerized innovation has delivered refined cameras, which can legitimately record superior quality advanced recordings.

Revised Manuscript Received on July 22, 2019.

M. Ramamoorthy, Department of CSE, Bharath Institute of Higher Education and Research, Chennai, Tamilnadu, India.

N.Ayyanathan, Department of CSE, B.S. Abdur Rahman Crescent. Institute of Science \& Technology, Chennai, India

M.Padma Usha, Department of CSE, B.S. Abdur Rahman Crescent. Institute of Science \& Technology. Chennai, India

S.Franklin, , Student,Department of CSE, Bharath Institute of Higher Education and Research, Chennai, Tamilnadu, India
Current IP reconnaissance cameras give up to multiple times the goals of customary simple cameras. The goals of IP cameras is commonly higher (right now up to 5 megapixels) and can catch a more clear picture when objects are moving. They likewise spread bigger territories, and offer unrivaled computerized zoom abilities. Today there is a developing requirement for productive Compression so as to diminish document measure for transmission and capacity necessity. Higher pressure proportion can be accomplished utilizing lossy pressure method, however this will prompt loss of data and may result in demonstrative blunders. Thus there is a need to store video in lossless configuration. Customary lossless pressure strategy results in low pressure proportion, the objective is to expand the pressure utilizing a lossless pressure apparatus. HEVC encoding can adequately abuse the fleeting and spatial repetition saw in video arrangement. There are such a significant number of uses, we required versatile video coding techniques for strength of the determination of spatial goals, fleeting goals and bit rate. In this strategy incorporates SNR versatility, spatial adaptability, and fleeting versatility to meet the prerequisites of packed video over remote systems or IP. Anyway the improvement layer can be truncated anytime to accomplish distinctive dimensions of value for the given transmission capacity prerequisite. For any information exchange needs more data transfer capacity portion to decrease gushing, anyway allotment can be predefined to be static or dynamic to make the transmission viable. For the most part powerful assignment be liked to oversee information traffic, clog control, productive supporting of pressure and coding.

\section{LITERATURE SURVEY}

\section{A. Review Stage}

Jeong-Hun Jang ,CTO,Illisis, Inc.Seoul, Republic of Korea 2016 "Adopted filter based object tracking and estimating colour histogram".

Stefan Muller-Schneiders, Thomas Jager, Hartmut S. Loos, Wolfgang Niem ,Robert Bosch GmbH,2005 "Surveillance Algorithm to improve the quality and resolution of the images".

Li-QunXu ,BT Research and Venturing, Group Chief Technology Office,2007 "Algorithm to Improve the security surveillance through encryption".

Guohua Wei, Member, IEEE, Dee Zhang, Shanshan $\mathrm{Wu}$ and Yulin Cao,2006How Encoding Algorithm is performed in the system ,Improving Coding efficiency phase by phase.

Qiu-Yun Zheng,School of computer Science \& Engineering Hunan University of Science 
Technology,TaoLi,Office of Student Administration Hunan University of Science and Technology,China,2011, Quality transmissions, Realizations for video transmission.

Video Enhancement for Medical and Surveillance Applications by Ramamoorthy et al. [21]. Proposed the figuring of foundation subtraction utilizing dynamic edge and a blend of Gaussian three fascinating strategies were utilized sensibly for article acknowledgment and analyzed their reason of execution on the exact locale and area. In laparoscope restorative methodology, a camera and light offer examination to the expert, who sees the comprehensive and video redesigned cautious portions on a TV screen. The video discernment framework outlines contrasts, after the thing cutting edge response, and development were settled.

\section{SYSTEM ARCHITECTURE}

The figure represents the IP based video surveillance system architecture.

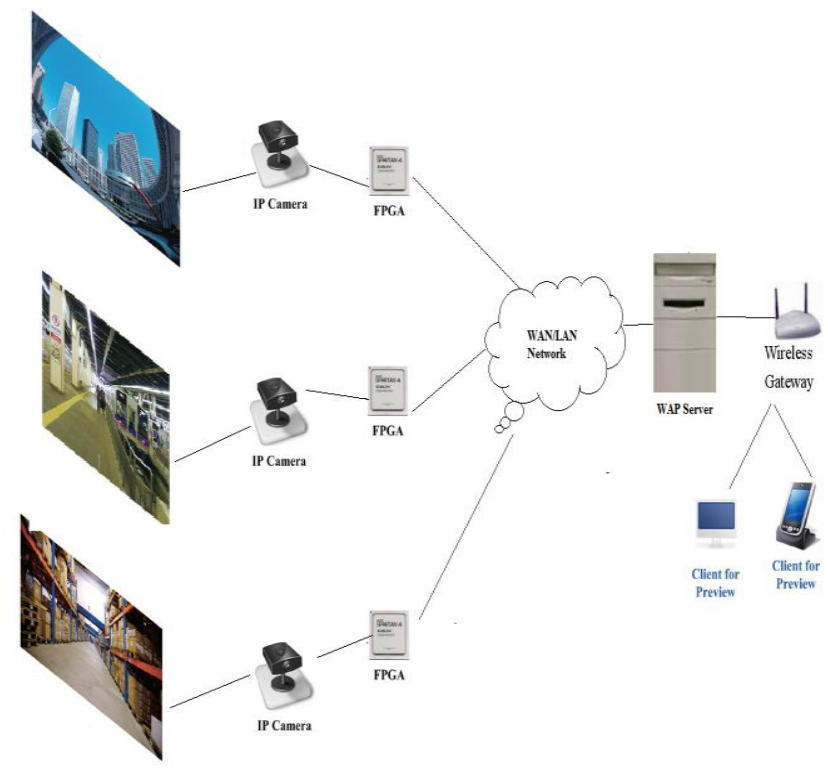

Fig. 1: System Architecture

Here the IP camera captures the video from the point of abstraction and transferred towards the FPGA board where itis interfaced. In FPGA based on the predefined algorithm to process the video noise reduction, enhancement, compression and coding were carried out and transferred to the client through the IP network. From the IP network the video can be retrieved and displayed through an embedded system or connected to the cell phone through WAP architecture.

The video transmission from the purpose of catch to the end show subjects to different changes. The initial phase in the process is to examine the caught simple video flag. The investigation can incorporate tasks, for example, sifting, simple to computerized change, calculation of change coefficients, or connection of the pixels with prestored vector quantization designs. A yield precision of such an examination shifts ordinarily from 8 to 12 bits. Generally no pressure is finished with the investigation. Information is just changed to an arrangement that is more compressible than the first flag group. The second step performs quantization of the flag, either lossless or lossy way. In a lossy framework the quantizer lessens flag exactness such that is satisfactory as conceivable to the eye. In the variable length coding obstruct each flag occasions will have a code with various number of bits. To get pressure, short codes are relegated to as often as possible happening occasions and long codes to inconsistent occasions.

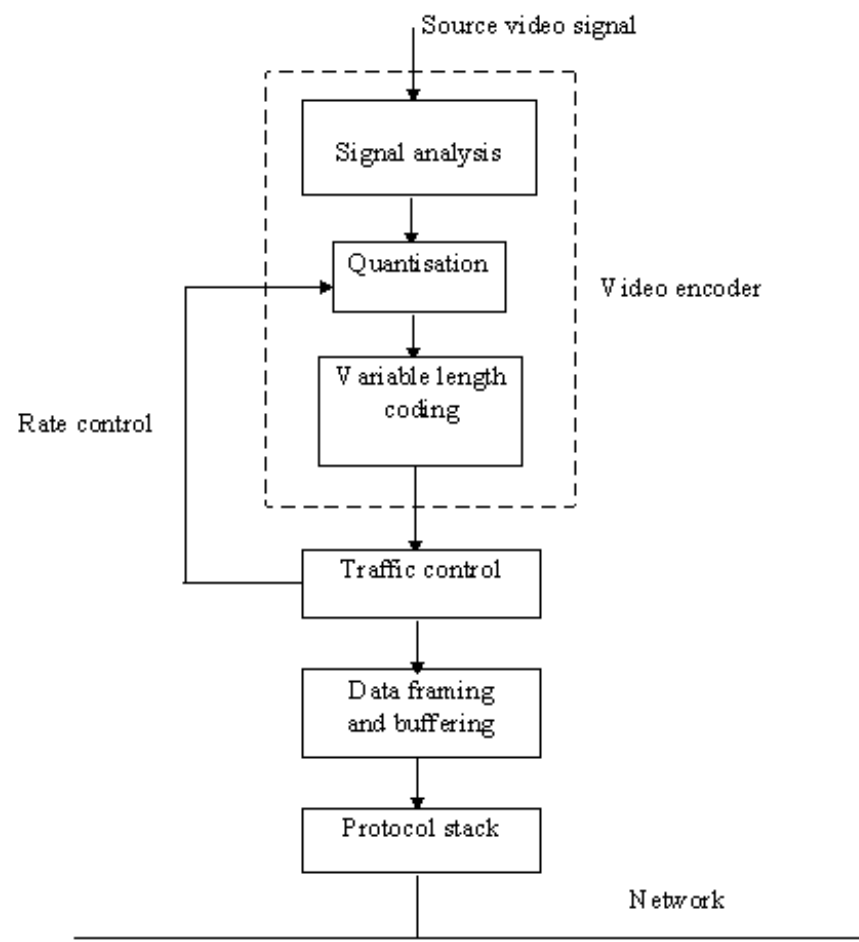

Fig. 2 Functional diagram for video data transmission

The most mind boggling some portion of a codec is the pack/decompress work. Codecs can do their work by equipment yet in addition by programming with quick processors. The primary objective of coding is the bit-rate decrease for capacity and transmission of the video source while holding video quality comparable to conceivable. There are various worldwide norms and furthermore numerous exclusive systems for advanced video pressure. The essential thought behind video pressure is to expel spatial excess inside a video edge and fleeting repetition between contiguous video outlines. This framework is increasingly adaptable and it very well may be expanded further at any reason. Additionally the expense of the framework is likewise exceptionally low when contrasted with some other frameworks.

\section{DESIGN AND IMPLEMENTATION}

In order to enhance the resolution and to reduce the transmission time several algorithms are performed in the hardware. In this system three algorithms are analyzed to optimize the performance and to design the system more efficient. In the following Section we discuss about the BM and $\mathrm{CCL}$ and HEVC algorithms in detail. 


\section{A. Background Modelling:}

The main aim of the BM is to find whether the considered pixel represents Background or Foreground. The Bayes model is used to find whether the given pixel represents background or foreground. This model computes the Bayes factor which is ratio of probability of the current pixel to be foreground or background. The Bayes factor is given by

$$
\mathrm{R}==
$$

Where is the pixel that is considered at the time t.If the value of $\mathrm{R}$ is small then the pixel belongs to the foreground and if the value of $\mathrm{R}$ is large then the pixel is considered to be the background data. The threshold value is fixed to consider the pixel is background or foreground.

The architecture of BM is given by,

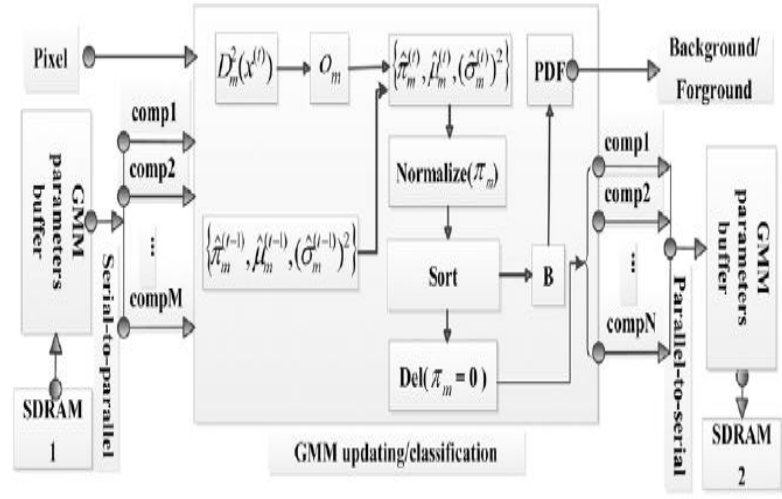

Figure 3: BM architecture

In this system we are considering for the video so the scene changes continuously so the pixel consideration also will change continuously.

The GMM with M components is given by

The GMM with M components is given by

$$
p\left(x^{(t)} \mid X_{v} B G+F G\right)=\sum_{m=1}^{M} \pi_{m}^{[t])} N\left(x^{(t)}{ }_{p} \mu_{m}^{(t)} \cdot\left(\sigma_{m}^{(t)}\right)\right.
$$

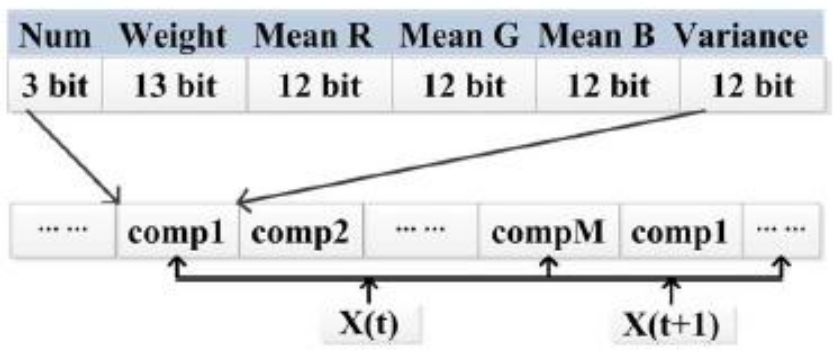

Figure 4: GMM system

\section{B. Connected Component Labeling (CCL):}

The associated part naming calculation is utilized to identify the associated district out of sight twofold pictures.
All the conceivable associated squares are acquired once after the setting the edge esteem. There are numerous calculation is utilized to perform CCL. Run-length encoding calculation is utilized to decrease certain successive tasks additionally it diminishes the handling time yet the multifaceted nature increments when it is performed in the FPGA. We use improved two pass calculation, in this calculation we filter a foundation picture in the raster style. A brief name to the picture pixel is given at the main pass and the changeless name is given to the picture pixel at the second pass.

The design for the CCL calculation that utilized in this framework is given by,

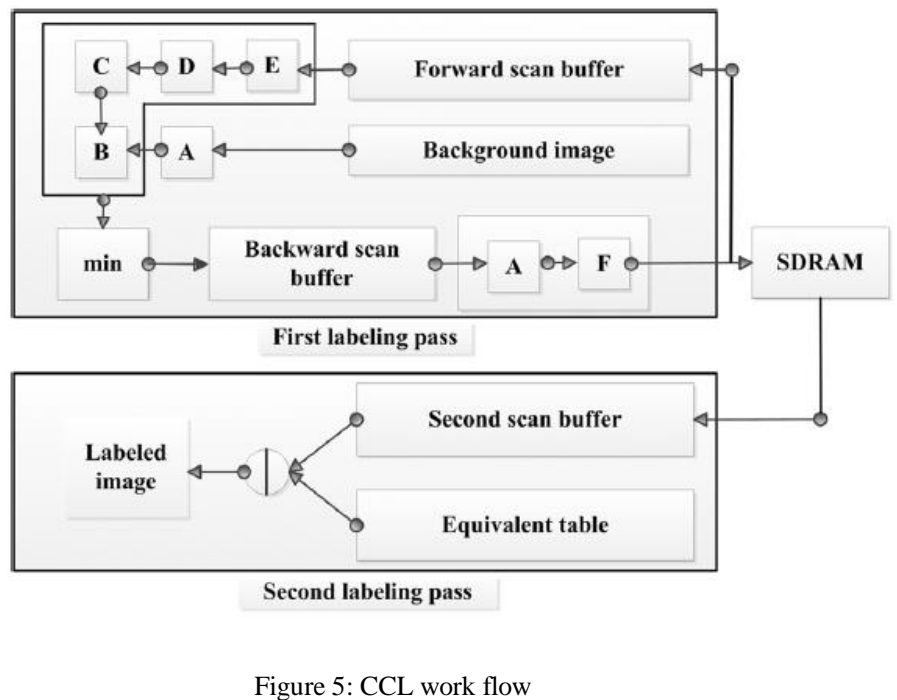

This calculation lessens the multifaceted nature to work with FPGA and has less computational unpredictability.

To spare preparing time, the regressive output is done trailed by the forward sweep. Around 1650 pixel timekeepers is utilized to transmit one line of 720p recordings , 1280 pixel clock is considered for forward checking process. What's more, just 370 pixel is staying for the regressive filtering. As appeared in the figure once the forward checking finished it is put away in the SDRAM. What's more, the last mark is gotten by the comparable table in the second procedure of naming.

\section{HEVC Coding Design:}

The main aim of the HEVC coding is coding efficiency, to ease the transport system and data loss resilience. In this algorithm each image is spitted to several blocks. First the sequence of video is coded using intra picture predictionmethod. The video encoded using HEVC has no external coding features. This coding standard provides about $50 \%$ increased quality of the video surveillance.

The overall work flow of the HEVC coding design is as shown in the figure. 
Robust Time Optimization in HD Video Surveillance System

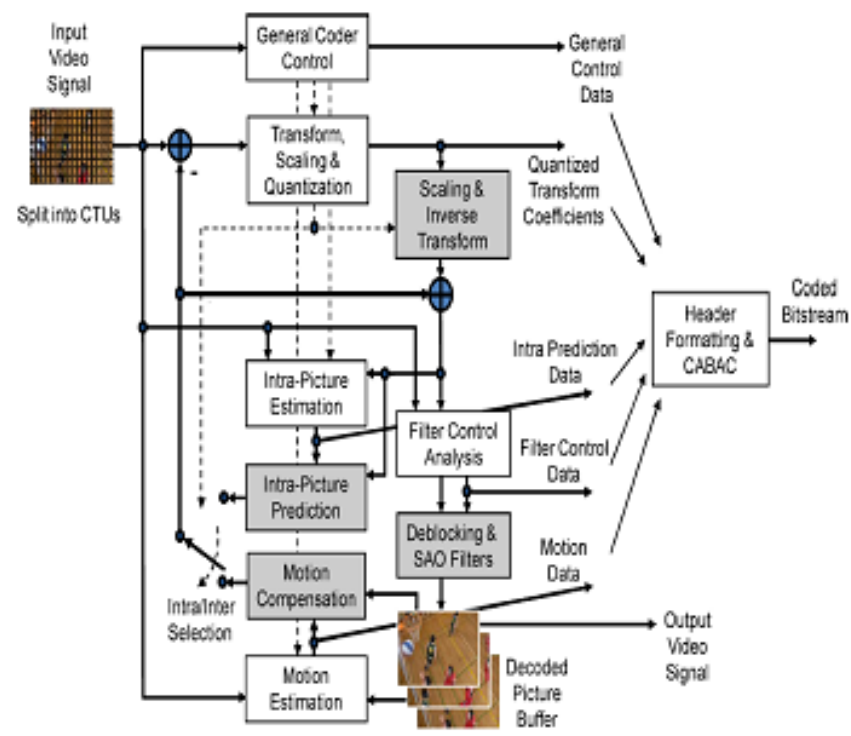

Figure 7: HEVC Decoder

\begin{tabular}{|c|c|c|c|}
\hline S.NO & Resolution & Frame rate & Bandwidth \\
\hline 1 & VGA $-640 \times 480$ & $12 \mathrm{fps}$ & $0.05 \mathrm{mbps}$ \\
\hline 2 & VGA $-640 \times 480$ & $25 \mathrm{fps}$ & $0.1 \mathrm{mbps}$ \\
\hline 3 & D1 $-704 \times 576$ & $12 \mathrm{fps}$ & $0.15 \mathrm{mbps}$ \\
\hline 4 & D1 $-704 \times 576$ & $25 \mathrm{fps}$ & $0.2 \mathrm{mbps}$ \\
\hline 5 & HD $-1280 \times 720$ & $12 \mathrm{fps}$ & $0.25 \mathrm{mbps}$ \\
\hline 6 & HD $-1280 \times 720$ & $25 \mathrm{fps}$ & $0.5 \mathrm{mbps}$ \\
\hline 7 & FHD $-1920 \times 1080$ & $12 \mathrm{fps}$ & $1 \mathrm{mbps}$ \\
\hline 8 & FHD $-1920 \times 1080$ & $25 \mathrm{fps}$ & $2 \mathrm{mbps}$ \\
\hline
\end{tabular}

\section{EXPERIMENTAL RESULTS}

The HEVC standard introduced here provides significant improvement in compression relative to existing standardsin the range of $50 \%$ bit rate reduction with perceptual video quality.

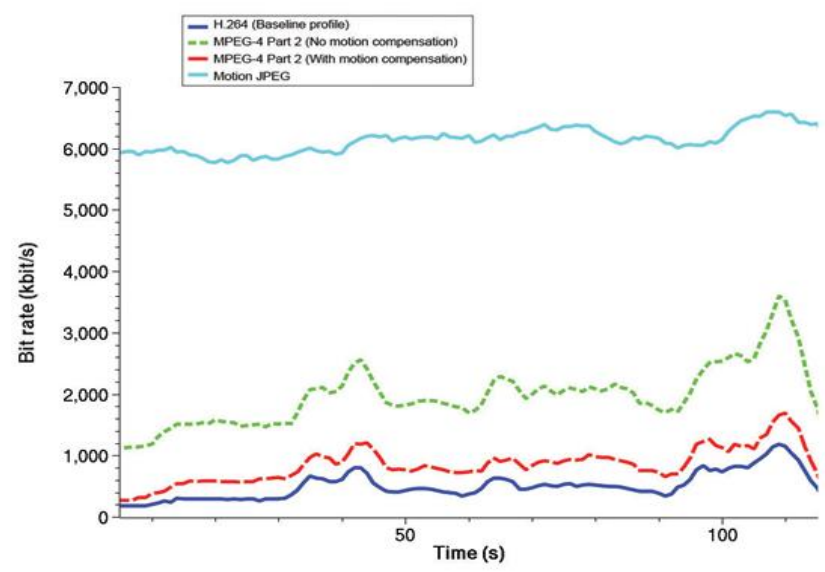

This algorithm mainly used to reduce the redundant pixels in the same frame or in the multiple frame. And this algorithm is newest of all video coding standard of the video experts group. HEVC significantly increases the compression efficiency.

The video coding standard HEVC/H.265 is up-gradation of H.264/MPEG-4 AVC. HEVC is mainly used in many other applications like Television signals transmitted through cable, satellite, mobile network, internet, Blu-ray Discs, video conferencing, video chat and Interactive systems. Also the syntax of HEVC is more generic so that it can be used for other application also and not only for the above applications.

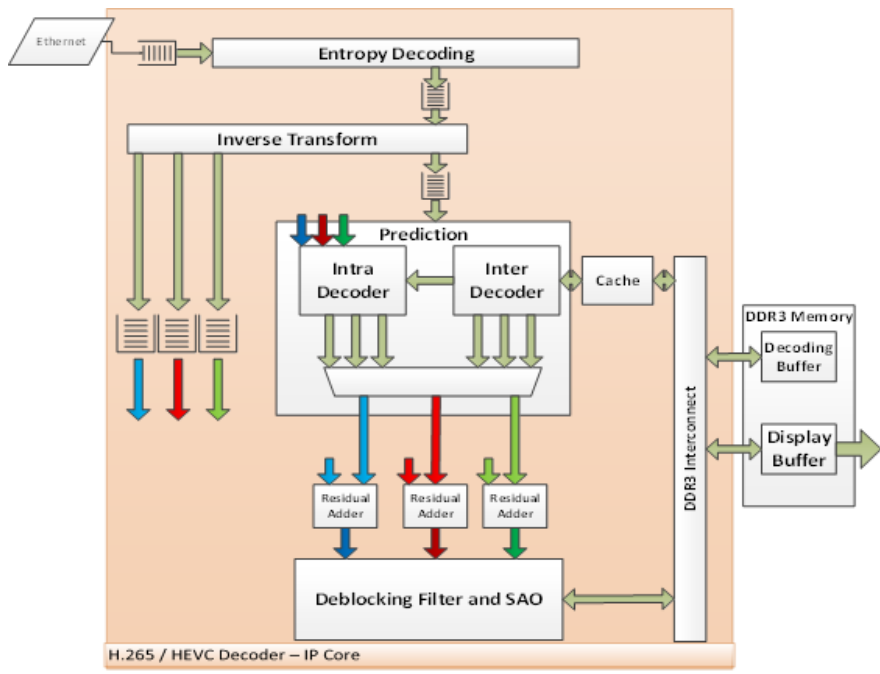

The below plot indicates the HEVC standard clearly outperforms with its predecessors in terms of coding efficiency

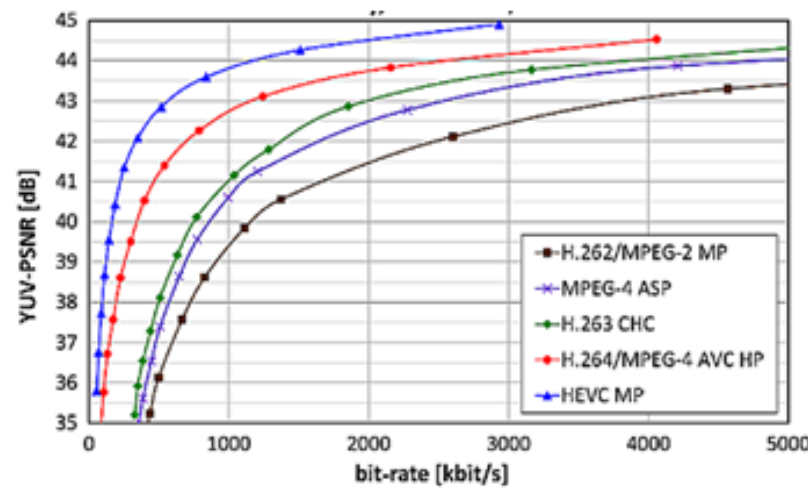

In order to design a VA algorithm an extensive

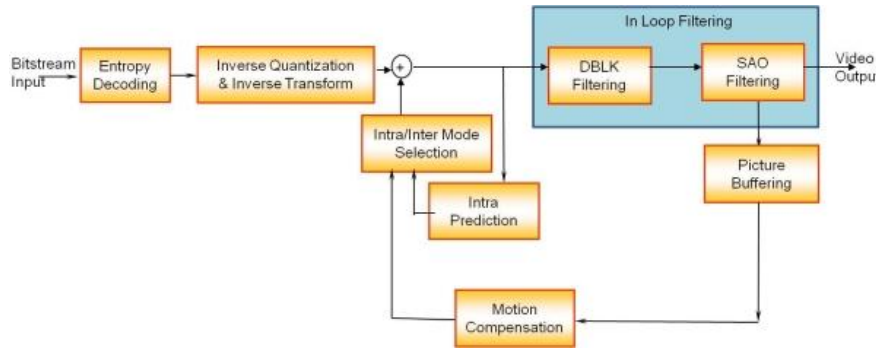

experiments are carried out. The algorithms are tested using PETS2001 dataset and the real time video is captured using IP cameras. The dataset PETS2001 has the resolution of 768 $\mathrm{X} 576$. The processing frames of CCL and BM is represented in the following 
TABLE I

COMPARISON OF MAXIMUM FRAME RATE ON FPGA AND GPU-BASED SERVER

\begin{tabular}{|l|l|l|}
\hline SYSTEM & RESOLUTION & FRAME RATE \\
\hline & & \\
\hline & $720 \mathrm{p}$ & $60 \mathrm{fps}$ \\
& $1080 \mathrm{p}$ & $30 \mathrm{ps}$ \\
\hline
\end{tabular}

The resource usage of FPGA implementation is given in the following table. We can see that the FPGA performs very well in both $720 \mathrm{p}$ and $1080 \mathrm{p}$ resolution. 'Na' represents that the time usage can be ignored.

\section{TABLE II}

TIME AND RESOURCE USAGE

\begin{tabular}{|l|l|l|l|}
\hline \multirow{2}{*}{ SYSTEM } & \multirow{2}{*}{ TIME USAGE } & \multicolumn{2}{l|}{ RESOURCE } \\
\cline { 3 - 4 } & & USAGE \\
\cline { 3 - 4 } & & LUTs & REGs \\
\hline BM & $16.67 \mathrm{~ms}$ & 5066 & 7781 \\
CCL & $33.33 \mathrm{~ms}$ & 10937 & 1534 \\
Single view tracking & $19.73 \mathrm{~ns}$ & 2676 & 2634 \\
others & NA & 4728 & 7659 \\
TOTAL & $33.3 \mathrm{~ms}$ & 23407 & 19608 \\
& & & \\
\hline
\end{tabular}

\section{CONCLUSION}

In this paper we proposed a system that enhance the video captured in the surveillance using HEVC, BM and CLL algorithms. The design of the system includes high quality IP camera interfaced to the FPGA array to connect with IP network Here different algorithms are examined using FPGA so that to achieveenhancement of video resolution and reduction of latency time. The system is further can be extended and connected to the mobile phones using the WAP server through the wireless gateway.

\section{REFERENCES}

[1] Kumaravel A., Rangarajan K.,Algorithm for automaton specification for exploring dynamic labyrinths,Indian Journal of Science and Technology,V-6,I-SUPPL5,PP-4554-4559,Y-2013

[2] P. Kavitha, S. Prabakaran "A Novel Hybrid Segmentation Method with Particle Swarm Optimization and Fuzzy C-Mean Based On Partitioning the Image for Detecting Lung Cancer" International Journal of Engineering and Advanced Technology (IJEAT) ISSN: 2249-8958, Volume-8 Issue-5, June 2019

[3] Kumaravel A., Meetei O.N.,An application of non-uniform cellular automata for efficient cryptography,2013 IEEE Conference on Information and Communication Technologies, ICT 2013,V-,I-,PP-1200-1205,Y-2013

[4] Kumarave A., Rangarajan K.,Routing alogrithm over semi-regular tessellations,2013 IEEE Conference on Information and Communication Technologies, ICT 2013,V-,I-,PP-1180-1184,Y-2013

[5] P. Kavitha, S. Prabakaran "Designing a Feature Vector for Statistical Texture Analysis of Brain Tumor" International Journal of Engineering and Advanced Technology (IJEAT) ISSN: 2249-8958, Volume-8 Issue-5, June 2019

[6] Dutta P., Kumaravel A.,A novel approach to trust based identification of leaders in social networks,Indian Journal of Science and Technology,V-9,I-10,PP--,Y-2016

[7] Kumaravel A., Dutta P.,Application of Pca for context selection for collaborative filtering,Middle - East Journal of Scientific Research,V-20,I-1,PP-88-93,Y-2014

[8] Kumaravel A., Rangarajan K.,Constructing an automaton for exploring dynamic labyrinths,2012 International Conference on Radar, Communication and Computing, ICRCC 2012,V-,I-,PP-161-165,Y-2012

[9] P. Kavitha, S. Prabakaran "Adaptive Bilateral Filter for Multi-Resolution in Brain Tumor Recognition" International Journal of Innovative Technology and Exploring Engineering (IJITEE) ISSN: 2278-3075, Volume-8 Issue-8 June, 2019

[10] Kumaravel A.,Comparison of two multi-classification approaches for detecting network attacks,World Applied Sciences Journal,V-27,I-11,PP-1461-1465,Y-2013

[11] Tariq J., Kumaravel A.,Construction of cellular automata over hexagonal and triangular tessellations for path planning of multi-robots,2016 IEEE International Conference on Computational Intelligence and Computing Research, ICCIC 2016,V-,I-,PP--,Y-2017

[12] Sudha M., Kumaravel A.,Analysis and measurement of wave guides using poisson method,Indonesian Journal of Electrical Engineering and Computer Science,V-8,I-2,PP-546-548,Y-2017

[13] Ayyappan G., Nalini C., Kumaravel A.,Various approaches of knowledge transfer in academic social network,International Journal of Engineering and Technology,V-,I-,PP-2791-2794,Y-2017

[14] Kaliyamurthie, K.P., Sivaraman, K., Ramesh, S. Imposing patient data privacy in wireless medical sensor networks through homomorphic cryptosystems 2016, Journal of Chemical and Pharmaceutical Sciences 92

[15] Kaliyamurthie, K.P., Balasubramanian, P.C. An approach to multi secure to historical malformed documents using integer ripple transfiguration 2016 Journal of Chemical and Pharmaceutical Sciences 9

[16] A.Sangeetha,C.Nalini,"Semantic Ranking based on keywords extractions in the web", International Journal of Engineering \& Technology, 7 (2.6) (2018) 290-292

[17] S.V.GayathiriDevi,C.Nalini,N.Kumar,"An efficient software verification using multi-layered software verification tool "International Journal of Engineering \& Technology, 7(2.21)2018 454-457

[18] C.Nalini,ShwtambariKharabe,"A Comparative Study On Different Techniques Used For Finger - Vein Authentication", International Journal Of Pure And Applied Mathematics, Volume 116 No. 82017 327-333, Issn: 1314-3395

[19] M.S. Vivekanandan and Dr. C. Rajabhushanam, "Enabling Privacy Protection and Content Assurance in Geo-Social Networks", International Journal of Innovative Research in Management, Engineering and Technology, Vol 3, Issue 4, pp. 49-55, April 2018.

[20] Dr. C. Rajabhushanam, V. Karthik, and G. Vivek, "Elasticity in Cloud Computing", International Journal of Innovative Research in Management, Engineering and Technology, Vol 3, Issue 4, pp. 104-111, April 2018

[21] K. Rangaswamy and Dr. C. Rajabhushanamc, "CCN-Based Congestion Control Mechanism In Dynamic Networks", International Journal of Innovative Research in Management, Engineering and Technology, Vol 3, Issue 4, pp. 117-119, April 2018

[22] Kavitha, R., Nedunchelian, R., "Domain-specific Search engine optimization using healthcare ontology and a neural network backpropagation approach", 2017, Research Journal of Biotechnology, Special Issue 2:157-166

[23] Kavitha, G., Kavitha, R., "An analysis to improve throughput of high-power hubs in mobile ad hoc network", 2016, Journal of Chemical and Pharmaceutical Sciences, Vol-9, Issue-2: 361-363

[24] Kavitha, G., Kavitha, R., "Dipping interference to supplement throughput in MANET" , 2016, Journal of Chemical and Pharmaceutical Sciences, Vol-9, Issue-2: 357-360

[25] Michael, G., Chandrasekar, A.,"Leader election based malicious detection and response system in MANET using mechanism design approach", Journal of Chemical and Pharmaceutical Sciences(JCPS) Volume 9 Issue 2, April - June 2016

[26] Michael, G., Chandrasekar, A.,"Modeling of detection of camouflaging worm using epidemic dynamic model and power spectral density", Journal of Chemical and Pharmaceutical Sciences(JCPS) Volume 9 Issue 2, April - June 2016

[27] Pothumani, S., Sriram, M., Sridhar, J., Arul Selvan, G., Secure mobile agents communication on 


\section{Robust Time Optimization in HD Video Surveillance System}

intranet,Journal of Chemical and Pharmaceutical Sciences, volume 9, Issue 3, Pg No S32-S35, 2016

[28] Pothumani, S., Sriram, M., Sridhar , Various schemes for database encryption-a survey, Journal of Chemical and Pharmaceutical Sciences, volume 9, Issue 3, Pg NoS103-S106, 2016

[29] Pothumani, S., Sriram, M., Sridhar, A novel economic framework for cloud and grid computing, Journal of Chemical and Pharmaceutical Sciences, volume 9, Issue 3, Pg No S29-S31, 2016

[30] Priya, N., Sridhar, J., Sriram, M. "Ecommerce Transaction Security Challenges and Prevention Methods- New Approach" 2016 ,Journal of Chemical and Pharmaceutical Sciences, JCPS Volume 9 Issue 3.page no:S66-S68 .

[31] Priya, N.,Sridhar,J.,Sriram, M."Vehicular cloud computing security issues and solutions" Journal of Chemical and Pharmaceutical Sciences(JCPS) Volume 9 Issue 2, April - June 2016

[32]

[33] Priya, N., Sridhar, J., Sriram, M. "Mobile large data storage security in cloud computing environment-a new approach" JCPS Volume 9 Issue 2. April - June 2016

[34] Anuradha.C, Khanna.V, "Improving network performance and security in WSN using decentralized hypothesis testing "Journal of Chemical and Pharmaceutical Sciences(JCPS) Volume 9 Issue 2, April - June 2016.

[35] Anuradha.C, Khanna.V, "A novel gsm based control for e-devices" Journal of Chemical and Pharmaceutical Sciences(JCPS) Volume 9 Issue 2, April - June 2016

[36] Anuradha.C, Khanna.V, "Secured privacy preserving sharing and data integration in mobile web environments " Journal of Chemical and Pharmaceutical Sciences(JCPS) Volume 9 Issue 2, April - June 2016.

[37] Sundarraj, B., Kaliyamurthie, K.P. Social network analysis for decisive the ultimate classification from the ensemble to boost accuracy rates 2016 International Journal of Pharmacy and Technology 8

[38] Sundarraj, B., Kaliyamurthie, K.P. A content-based spam filtering approach victimisation artificial neural networks 2016 International Journal of Pharmacy and Technology 83 .

[39] Sundarraj, B., Kaliyamurthie, K.P. Remote sensing imaging for satellite image segmentation 2016 International Journal of Pharmacy and Technology $8 \quad 3$.

[40] Sivaraman, K., Senthil, M. Intuitive driver proxy control using artificial intelligence 2016 International Journal of Pharmacy and Technology $8 \quad 4$.

[41] Sivaraman, K., Kaliyamurthie, K.P. Cloud computing in mobile technology 2016 Journal of Chemical and Pharmaceutical Sciences 92.

[42] Sivaraman, K., Khanna, V. Implementation of an extension for browser to detect vulnerable elements on web pages and avoid click jacking 2016 Journal of Chemical and Pharmaceutical Sciences 92.

\section{AUTHORS PROFILE}

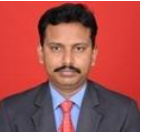

M. Ramamoorthy, Department of CSE, Bharath Institute of Higher Education and Research, Chennai, Tamilnadu, India

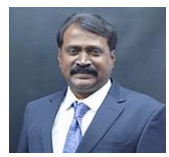

N.Ayyanathan, Department of CSE, B.S. Abdur Rahman Crescent. Institute of Science \& Technology, Chennai, India

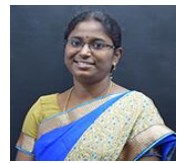

M.Padma Usha, Department of CSE, B.S. Abdur Rahman Crescent. Institute of Science \& Technology. Chennai, India

S.Franklin, Student, Department of Computer Science \& Engineering, Bharath Institute of Higher Education and Research, Chennai, India 